\title{
Higher education dominance and siloed knowledge: a systematic review of flipped classroom research
}

Open Access

Mona Lundin * (D), Annika Bergviken Rensfeldt, Thomas Hillman, Annika Lantz-Andersson and Louise Peterson

\author{
* Correspondence: \\ mona.lundin@ped.gu.se \\ Department of Education, \\ Communication and Learning, \\ University of Gothenburg, Box 300, \\ SE-405 30 Göteborg, Sweden
}

\begin{abstract}
This structured review examined (academic) publications on flipped or inverted classrooms based on all Scopus database $(n=530)$ references available until mid-June 2016. The flipped or inverted classroom approach has gained widespread attention during the latest decade and is based on the idea of improving student learning by prepared self-studies via technology-based resources ('flips') followed by high-quality, in-class teaching and learning activities. However, only a few attempts have been made to review the knowledge of the field of interest more systematically. This article seeks to address this problem and investigates what constitutes the research on flipped classrooms and, in particular, to examine the knowledge contributions with the field so far in relation to the wider research topic of educational technology. This review found that the current state of flipped classrooms as a field of interest is growing fast, with a slight conference preference and a focus on higher education and STEM (science, technology, engineering and math) area contributions, with the US as the predominant geographical context. It is concluded that studies on flipped classrooms are dominated by studies in higher education sector and are relatively local in character. The research tends not to interact beyond the two clusters of general education/educational technology and subject-specific areas. This implies that knowledge contributions related to the flipped classroom approach are relatively siloed and fragmented and have yet to stabilise. Academically and socially, the research is quite scattered, and only local evidence and experiences are available. The knowledge contributions within this field of interest seem to be anecdotal rather than systematically researched. To a large extent, the research lacks anchoring in, for example, learning theory or instructional design known from educational technology traditions and which would have helped much of the flipped classroom research to examine aspects of the flipped classroom approach more fully.
\end{abstract}

\section{Introduction}

The increase of user-generated and collectively shared knowledge content on the Internet has affected education and teaching in a variety of ways. One particularly popular approach for teachers to produce and share knowledge content as part of their professional practices is the so-called flipped or inverted classroom approach. The basic purpose of flipping the classroom, often ascribed to Bergmann and Sams (2012a, 2012b), is to reallocate activities traditionally conducted within the classroom, such as lectures, to educational resources that students engage with before attending class. This

(c) The Author(s). 2018 Open Access This article is distributed under the terms of the Creative Commons Attribution 4.0 International License (http://creativecommons.org/licenses/by/4.0/), which permits unrestricted use, distribution, and reproduction in any medium, provided you give appropriate credit to the original author(s) and the source, provide a link to the Creative Commons license, and indicate if changes were made. 
reallocation is intended to free classroom time for creating meaningful learning situations for in-class interaction between students and teachers. For realising the flipped or inverted classroom approach, social media has become an important platform for sharing educational resources in the form of blog posts, YouTube videos or other media through social networking sites. Combined with the use of social networking to share educational resources with students, social media communities have also become important sites for mobilising educators within the flipped or inverted classroom movement through the sharing of experiences and resources (e.g., Cho, Ro, \& LittenbergTobias, 2013; Duncan-Howell, 2010). The movement can both be characterised by its grassroots-level formation and by its teaching-practice orientation with a heavy focus on knowledge content development, epitomised by 'the flip' itself. In this paper, we review the existing research literature available on the flipped or inverted classroom as an approach and as a movement.

During our preliminary explorations of the literature, we noticed that the search for evidence of the effectiveness of and improvements engendered by the flipped or inverted classroom approach is becoming frequent. This is illustrated by several recent articles in international journals on higher education studies (Flores, del-Arco, \& Silva, 2016; Kim, Kim, Khera, \& Getman, 2014; Nouri, 2016; O’Flaherty, Phillips, Karanicolas, Snelling, \& Winning, 2015; Park, Yu, \& Jo, 2016; Westerman, Daniel, \& Bowman, 2016). Based on this development, it is timely to systematically review this emerging field of research and, in particular, the field's contribution to shared knowledge on the flipped or inverted classroom phenomenon. By conducting a systematic review, our interest has been to explore the focus of the most-cited research and how research on the flipped or inverted classroom approach and movement as a field of interest is developing within the educational sector. As both advocates and critics continue to discuss the effectiveness of the approach, it is important to openly approach and scrutinise the knowledge claims of the field while providing a well-grounded and systematically mapped analysis of existing research.

As our review will show, a rich spectrum of local experiments and experiences on the approach have been reported in a wide array of publication forms. This variety informed our choice of research review methodology and our selection of the multidisciplinary abstract and citation database Scopus (www.scopus.com). The review covers all peer-reviewed publications on the topic of flipped or inverted classrooms published between the beginning of 2000 and mid-June 2016. As we will show, there was a considerable increase in research contributions in the period between 2012 and mid-June 2016 and in particular from the higher education area, with the term 'flipped classroom' becoming more common and the previously widespread term 'inverted classroom', used in the first publication on the topic (Lage \& Platt, 2000, losing ground. Hereafter we will only refer to the term flipped classroom and assume that it also includes the term inverted classroom.

Only a few reviews of the research on flipped classrooms have been conducted so far (e.g., Bishop \& Verlinger, 2013; O'Flaherty et al., 2015). In their recent paper from Internet and Higher Education, O'Flaherty et al.'s (2015) review offers one of the more recent and noteworthy accounts of the field of interest through 
a scoping method focussed on explicitly identified higher education references. The review is mainly concerned with evidence of how the approach could be improved through 'the exploration of key aspects of the flipped class that influence its effectiveness and contribute to an improved student flipped learning experience' (p. 86). Their conclusion is that the current research lacks a shared conceptual framework for understanding learning (both in pre-class, post-class and faceto-face learning activities),

resulting in a lack of clarity and heavy content focus; an under-developed capacity to blueprint, that is, to translate conceptual frameworks into context-specific plans and a lack of understanding of how to design and support inquiry-based learning and metacognition in a flipped learning curriculum. (O’Flaherty et al., p. 94)

Thus, their review points to several problematic aspects of the current developments within the higher education research field, including a technology-driven orientation that neglects learning aspects and an insufficient capacity for developing shared knowledge and a conceptualisation of the approach. Our review complements this earlier scoping review with more current data and seeks to address the current state of research on the flipped classroom more comprehensively by conducting a systematic research review across the literature with the intention of generating a broader impression of the field of interest that can then be discussed in relation to higher education. As part of this review, we will first explore the knowledge base and claims made in the available research and then discuss the contributions and developments of this emerging field.

\section{Aim and research questions}

The overall aim of our systematic review is to investigate what constitutes the research on flipped classrooms and in particular to examine the knowledge contributions within the field so far and relate them to the wider research topic of educational technology in relation to higher education. The research questions that guided this review are as follows:

- How can the field of interest around the flipped classroom approach be described and problematised based on the most-cited publications?

-What characterises the studies in terms of focus, setting (educational system, academic subject and country), methods and empirical data? How does the research interact?

- What kind of knowledge is this field of interest aiming to develop?

- What can be said of the current state of the field as an approach and a movement, and what future research is needed?

The questions can be classified into two areas of interest: one more descriptivequantitative for mapping current research and one more epistemological-qualitative to understand the its knowledge foundations and developments of the field. Each of these areas of interest will be developed further in the remainder of this paper. 


\section{Methods and methodological approach}

Our choice to conduct a systematic research review process is based on the need to develop systematic knowledge around the flipped classroom approach. The knowledge contributions of this emerging field of research are still in the making, and a systematic review should be of use for practitioners, scholars and stakeholders. One particular concern is how this field of interest is emerging and interacting within the wider research domains of educational technology. Earlier analyses of the research characteristics of educational technology, which include scientific areas such as educational science, cognitive psychology and computer science, also inform our analysis. Bulfin, Henderson, Johnson, and Selwyn's (2014) survey of methodological preferences based on 462 researchers showed that the research field of educational technology has a preference for descriptive and qualitative studies. Furthermore, Kalz and Specht's (2014) scientometric analysis of 3,476 scientific publications within technology-enhanced learning illustrates that disciplinary variety and a crossdisciplinary nature are common features. As part of our work, we also considered the impact of systematic, evidence-based research methodology, including how it has been criticised, e.g., in educational science (Biesta, 2007; Denzin, 2009; Hammersley, 2001). We agree with the critique that too much emphasis on the quantification of research and education performances for the purposes of comparability and impact for competitiveness is problematic, especially within fields characterised by a cross-disciplinary nature, local ideological education differences as well as commercial technology interests. However, taking this critique into account, we found it useful to combine quantitative selection principles with qualitative, indepth analyses and a problematising stance towards reviewing in our analysis of the emerging research on the flipped classroom approach.

We have chosen to describe research on the flipped classroom approach as a field of interest, as the research currently has no stable disciplinary basis or established claims of validity (see, for example, Whitley, 2000). However, the research that has emerged to date socially and collectively shares rather similar views of the approach itself, the technology used and the need for recognition from practitioners. Based on these characteristics, we have chosen citation frequency as a selection instrument as the most-cited references are presumed to have a certain social impact. Citation frequency is thus not taken to be a proxy for quality but as an indicator of which texts are widely used in this emerging field of research.

With our choice of methods and tools for the selection and analysis of data, the aim was to make the research process as transparent as possible in terms of systematic and conceptual positions. Consequentially, our review has been carried out following the nine tasks for systematic reviews suggested by Gough (2007, p. 218-219):

(1) establishing the review question and protocols

(2) defining studies to be included or excluded

(3) articulating the search strategy and choosing information sources

(4) screening the articles based on the inclusion/exclusion criteria

(5) mapping the results of the search strategy in a flowchart

(6) extracting relevant descriptive data from included studies

(7) appraising the methodological quality of included studies 
(8) synthesising, either by aggregating or interpreting the contributions of the included studies

(9) communicating and discussing the synthesis

With the review questions and protocols defined, we conducted a search for flipped classroom-related literature on June 22nd, 2016, in Elsevier's Scopus database. Initially we tested both Scopus and Thomson-Reuters's Web of Knowledge (now Web of Sciences and maintained by Clarivate Analytics) for comparisons based on similar search queries. Scopus was selected as it covers a wider array of peer-reviewed references and is more multidisciplinary in character (with scientific, medical, social sciences, the arts and humanities and technical literature included). The particular search string used in Scopus was 'TITLEABS-KEY (flipped OR inverted) AND TITLE-ABS-KEY (classroom)'. This search term queried the database for all results where the terms 'flipped classroom' or 'inverted classroom' appear in the title, abstract or keywords of publications. The search produced 530 records consisting of journal articles and conference proceeding papers. In the flow chart shown in Fig. 1, the selection of records using the Scopus results has been described. Important aspects of the process will be discussed further.

In step 1, 530 publications were identified. While we did not examine the number of false positives produced by the search criteria for this step, such an examination was performed for the most-cited publications in step 2, and it is reasonable to assume that the false-positive rate of $16 \%$ identified for highly cited

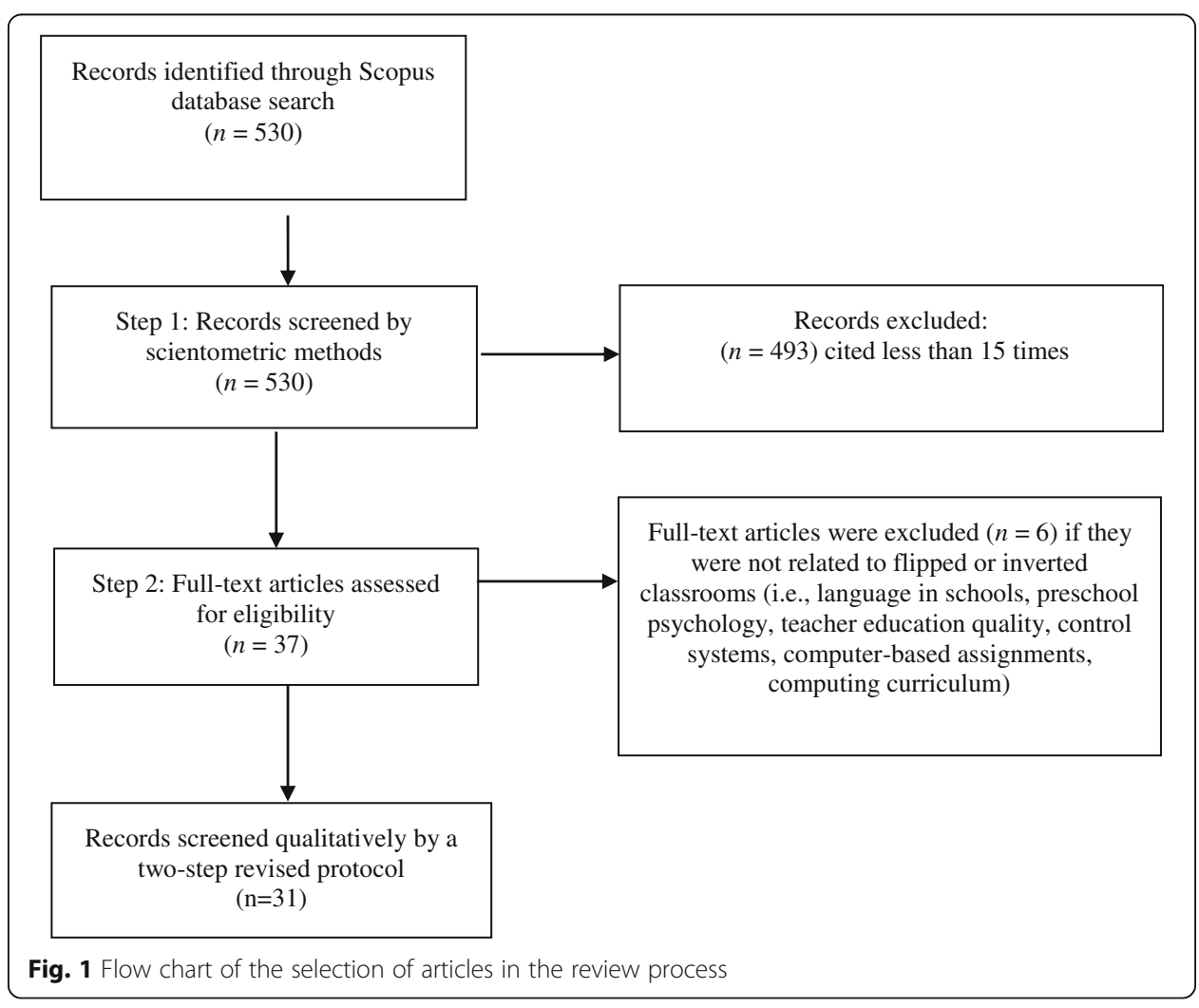


publications is similar to the rate for the wider dataset. For the publications identified in step 1, both descriptive as well as aggregated analyses of co-occurrences of keywords and records were conducted to find relevant information about the dataset. For processing the data retrieved from Scopus, we used several tools, including Microsoft Excel for basic processing and sorting, and Elsevier's Mendeley as a reference manager tool. Co-occurrence analyses were conducted using VOSviewer (van Eck \& Waltman, 2010) and Yasu Imao's CasualConc application (sites.google.com/site/casualconc/), and the results are presented in the step 1 subsection of the results section.

In step 2 of the review process, a further selection and extraction phase was conducted where 37 publications cited 15 or more times were selected for manual screening by a review panel based on an extended review protocol. All references were given an identification number from 1 to 37, where number 1 was the most cited. These identification numbers have also been used to identify the publications in the results section. There were 6 publications that were excluded (numbers 16, 21, 27, 34, 36 and 37) since they were determined to be unrelated to the flipped or inverted classroom approach during manual screening (a falsepositive rate of 16\%). The remaining 31 records are included in Appendix 1, and the excluded false-positive publications are listed in Appendix 2. The manual screening of the 31 records was based on a protocol-driven process, resulting in 2 protocols and adherent questions that formed the basis for the records listed in Appendix 1. The results of step 2 are presented in the step 2 subsection of the results section.

In step 2, the 31 selected records were first classified based on the metadata of the author, year, title, source title, volume/issue/pages, citations, document type and URL. The publications were then distributed amongst a panel of research project team members for further examination based on a shared protocol. The protocol was iterated and is reported in Appendix 1. The following questions were examined and reported first for each publication:

- What keywords are declared for the publication?

- Does the publication refer to a specific country, where is the study conducted?

- Did the publication undergo peer review or not?

- What type of publication is it (article, conference paper, editorial, etc.)?

- Which domain or educational sector does the publication concern?

- What is the character of the publication-practitioner report, academic contribution or other?

- What is the finding or conclusion of the publication, e.g., improving practice or learning?

- Based on the above, is the publication of high, low or medium relevance for the review?

The protocol was then expanded with the following questions:

- What are the aim/focus/research questions mentioned, with specific regard to the verbs used (develop, implement, evaluate, etc.)? 
- Are pedagogical/learning theories mentioned, and, if so, are they implicit or explicit? Are theories robustly used, referenced and explained, or are more everyday, ad hoc buzzword orientations used?

- What is the quality of the method and references used? Is the quality low, medium or high? Lower quality is defined as, e.g., smaller populations, relying on local case studies/in-house experiences and no explicit methodology or theoretical base, and higher quality is defined as, e.g., the methods are explained, analytical tools are provided, methodological considerations are included and theoretical references are used.

This systematic review is a part of a larger research project on the flipped education movement (funded by the Swedish Research Council 2015-2017). In parallel to the review process, the project team gained insight into the field based on interviews, surveys and large-scale computational statistics on the approach and relevant social media communities. All five of the project members constituted a review panel for this systematic review and contributed to a protocol-driven, iterative process of reviewing. All protocols were synthesised, discussed and also refined to improve the design of the review throughout the process. In addition, to account for intersubjective validity and problems of bias, different members of the review panel examined a random sample of the records, and two panel members verified all excluded records. In the next section, the results of step 1 and step 2 of the review process are presented, followed by a discussion of the synthesis developed from the results of the process.

\section{Results}

The results of this systematic review will be presented under two headings referring to the two steps in the review process. First, we provide a descriptivequantitative mapping and aggregation of the current research based on the 530 most-cited publications from step 1 in the review. Second, we present descriptive-quantitative data from step 2, mapping the flipped classroom research based on those 31 publications cited 15 or more times due to our interest in the most used publications in the field. Included here are analyses of the types of knowledge contributions made in the reviewed literature with regard to overall research characteristics as well as the epistemological basis for the field of flipped classroom research.

\section{Step 1: Characteristics of the flipped classroom field of interest}

To provide a context for flipped classrooms as a field of interest, some basic characteristics of the sample of the 530 most-cited publications are presented. The first characteristic concerns a substantial growth of publications starting in 2011 (Fig. 2). Here, we have not taken the $16 \%$ of publications that were false positives into account, as the aim of this part of the results is to characterise the emerging field of interest in relative terms.

Figure 2 shows that the rate of academic publications concerned with flipped classrooms increased substantially between 2011 and the end of 2015. This period started 


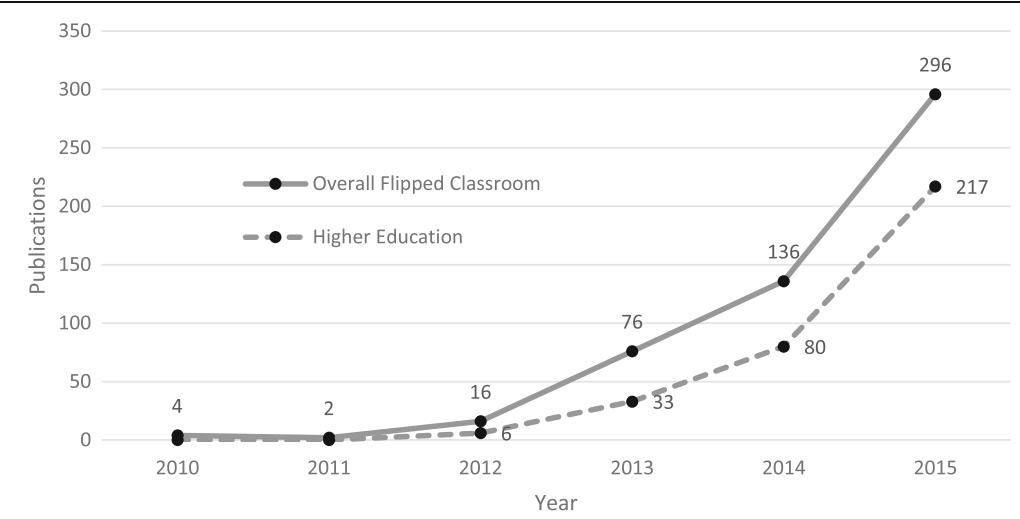

Fig. 2 Publications by year for flipped or inverted classrooms generally and higher education specifically

with two publications in 2011, followed by 16 publications in 2012, 76 publications in 2013, 136 publications in 2014, and 296 publications in 2015. This substantial increase in the number of academic publications concerned with flipped classrooms indicates, we will argue, an emerging movement of the flipped classroom as a field of interest. This is underscored in relation to higher education, where the proportion of those publications with 'higher education' in the title, keywords or abstract within the overall corpus is significant. In 2012, higher education publications represented $38 \%$ of the total number, while by 2015 they represented 73\%. This indicates a particularly strong growth of interest in relation to higher education and suggests that higher education has come to dominate the scientific discourse around the flipped classroom phenomenon.

Geographically, the research on flipped classroom is dominated by publications from the United States. Despite some contributions from countries such as India and Malaysia, the Global South is generally underrepresented in our corpus, and largely English-speaking countries dominate (see Table 1).

Similar distributional patterns are seen in the research review by O'Flaherty et al. (2015), but our data highlights the relatively low number of contributions from European countries. While much of the U.S. dominance in publications could be accounted for by a general Anglo-Saxon dominance in academic publishing, it should also be noted that the flipped classroom approach was first popularised in secondary education

Table 1 Publications by country of first-author affiliation

\begin{tabular}{llllll}
\hline United States (321) & Norway (9) & Finland (4) & Qatar (3) & Switzerland (2) & Iran (1) \\
Australia (31) & India (8) & Greece (4) & Saudi Arabia (3) & Austria (1) & Oman (1) \\
China (26) & Malaysia (7) & South Korea (4) & Sweden (3) & Bahrain (1) & Poland (1) \\
Canada (17) & Japan (6) & Turkey (4) & Thailand (3) & Chile (1) & Russia (1) \\
United & Spain (6) & Denmark (3) & Israel (2) & Colombia (1) & Saint Kitts and \\
Kingdom (16) & & & & Nevis (1) \\
Germany (14) & Brazil (5) & France (3) & The Netherlands (2) & Croatia (1) & Sudan (1) \\
Taiwan (14) & Hong Kong (5) & Ireland (3) & Puerto Rico (2) & Egypt (1) & Undefined (8) \\
Italy (10) & Singapore (5) & New Zealand (3) & South Africa (2) & Indonesia (1) & \\
\hline
\end{tabular}


by two teachers, Bergmann and Sams (2012a, 2012b), both of whom are active within the U.S. educational context. Similarly, as the second-most prolific country, Australia's educational context has a strong tradition of technology-based and student-centred education forms that may well set the stage for strong engagement with the flipped classroom approach.

Overall, within the corpus, conference papers are the dominant form of publication, accounting for $55 \%$ of publications with journal articles making up the remaining $45 \%$. However, this trend appears to be shifting, with a decrease in the relative dominance of conference papers in 2014 and 2015. The early dominance of conference papers over journal articles may be partly due to the flipped classroom being a rather new field of interest, where conference papers are used as a format for sharing preliminary results. Within our corpus, the most common publication venue is the proceedings of the American Society for Engineering Education's (ASEE's) Annual Conference and Exposition with 84 publications. The second-most common publication venue is the proceedings of the Frontiers in Education Conference of the Institute of Electrical and Electronics Engineers (IEEE) with 33 publications. This suggests that both ASEE's Annual Conference and Exposition and IEEE's Frontiers in Education Conference are publication venues used by researchers and practitioners to channel preliminary results to the engineering education community. It is not until the third-most common publication venue, PRIMUS: Problems, Resources and Issues in Mathematics Undergraduate Studies with 24 publications, that a journal appears. To sum up so far, the flipped classroom as a field of interest is currently engaged with sharing experiences and methods about the flipped classroom approach by providing preliminary results in conference proceedings and in journal articles, the former of which are slightly predominant. What is interesting is that such sharing of experiences and methods seems to be carried out within specific subject fields or educational domains, predominantly higher education, along with specific subject areas, such as engineering education, computer science and mathematics education.

The majority of the publications in our corpus are associated with a particular subject area, distributed as follows: social sciences (329 publications, $62 \%$ total), computer science (199 publications, 38\% total), engineering (162 publications, 31\% total), medicine (47 publications, 9\% total) and mathematics (35 publications, 7\% total). This implies that the most-cited publications related to flipped classrooms can be located in well-defined subject areas, and as illustrated before, commonly within the STEM (science, technology, engineering, mathematics) areas.

Based on co-occurring citations, that is, the interaction of publications as they refer to each other, we can see the dominance of STEM areas again, particularly engineering, natural science and medicine. Within the data, two strong clusters are formed: one in the subject-specific higher education domain (marked in red in Fig. 3) and another representing the domains of general education and educational technology (marked in green in Fig. 3). Within the educational technology domain, three journals dominate: Computers \& Education, Educational Technology \& Society, and British Journal of Educational Technology. Closely following these are the 


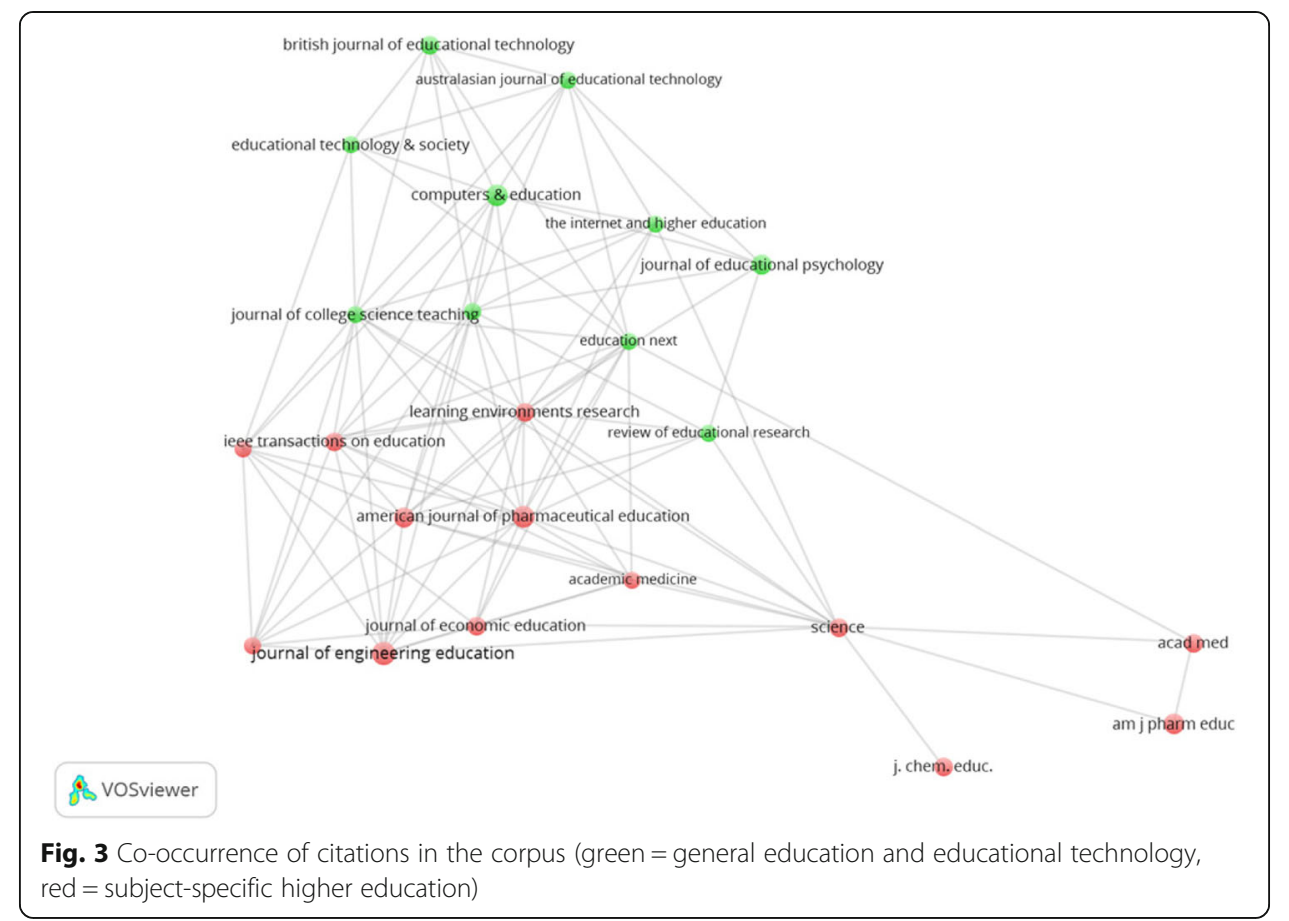

Internet and Higher Education and the Australasian Journal of Educational Technology. Again, the growing importance of journal publications within this field is made visible. Generally, there is a relatively low degree of interaction within the field as a whole, with the exception of some parts of the subject-specific areas and among certain conference publication venues. This suggests that much of the research discourse on flipped classrooms is constrained to clusters and in particular subject-specific silos, most often within the STEM higher education area (Fig. 3). The source data and co-citations within these fields suggests that studies on the flipped classroom phenomenon remain relatively local in character and tend not to refer to publications outside of their respective field clusters or get cited outside of those clusters. Only parts of the subject-specific domain show a strong discourse of internally citing earlier studies. This lack of interaction between fields, visible in Fig. 3, implies that the knowledge contribution of the flipped classroom as a field of interest has yet to stabilise. Academically and socially, the research is characterised by a low degree of interaction and a significant divide between the general education/educational technology areas and subject-specific domains.

To summarise this first result section based on descriptive-quantitative data from our corpus of the 530 most-cited publications, the current state of the flipped classroom as a field of interest can be described as growing fast with a slight preference for conference proceedings and a predominance of STEM and medical contributions. Furthermore, as the field of flipped classrooms seems to be fragmented with low interactivity, it also reflects trends in research within the wider field of educational technology. As argued by Selwyn (2012), research on educational technology is constituted by 'different tribes', each with a 'particular interest and motives for studying technology and education' (p. 213). Such tribal work leaves little 
'collective impetus for making the field anything more than the sum of its parts' (p. 213). In the context of the flipped classroom, such isolated tribes and local subject area studies are manifested in the evident lack of interaction between subject fields. The data shows that the focus of most studies on flipped classrooms is subject-specific instructional designs.

\section{Step 2: Mapping flipped classrooms as a field of interest}

In this section, we present those 31 publications cited 15 or more times in our corpus of 530 records from step 2. First, 37 publications were selected on the basis that they had received 15 or more citations. Six of these publications were identified as false positives that did not actually address the flipped classroom approach, resulting in a selection of the 31 most-cited publications on flipped classrooms. This list of most-cited publications confirms the predominance of American researchers as 30 of the 31 records has a first author affiliated with a U.S. institution. All published by U.S.-based researchers, the top 6 publications were cited 50 or more times. These publications are presented in Table 2.

The six most-cited studies use a variety of concepts to describe the teaching strategies employed, and most of them combine the concepts in their definitions. The most common concepts used are the flipped classroom approach (Mason, Shuman, \& Cook, 2013; McLaughlin et al., 2014; Prober \& Khan, 2013; Strayer, 2012; Tucker, 2012) and the inverted classroom (Gannod, Burge, \& Helmick, 2008; Mason et al., 2013; Strayer,

Table 2 Location, publication type, publication source's impact factor and number of citations of the 6 most-cited publications in the field of flipped classrooms

\begin{tabular}{|c|c|c|c|c|c|c|}
\hline $\begin{array}{l}\text { (Study number) } \\
\text { author details }\end{array}$ & Year & $\begin{array}{l}\text { Type of } \\
\text { publication }\end{array}$ & Title & $\begin{array}{l}\text { No. of } \\
\text { citations }\end{array}$ & Publisher & $\begin{array}{l}\text { First author } \\
\text { location }\end{array}$ \\
\hline (1) Strayer & 2012 & Article & $\begin{array}{l}\text { How learning in an } \\
\text { inverted classroom } \\
\text { influences cooperation, } \\
\text { innovation and task } \\
\text { orientation }\end{array}$ & 142 & $\begin{array}{l}\text { Learning Environments } \\
\text { Research }\end{array}$ & US \\
\hline (2) Tucker & 2012 & Note & $\begin{array}{l}\text { The flipped classroom: } \\
\text { Online instruction at } \\
\text { home frees class time } \\
\text { for learning }\end{array}$ & 121 & Education Next & US \\
\hline $\begin{array}{l}\text { (3) McLaughlin } \\
\text { et al. }\end{array}$ & 2014 & Article & $\begin{array}{l}\text { The flipped classroom: } \\
\text { A course redesign to } \\
\text { foster learning and } \\
\text { engagement in a health } \\
\text { professions school }\end{array}$ & 84 & Academic Medicine & US \\
\hline $\begin{array}{l}\text { (4) Mason, Shuman } \\
\& \text { Cook }\end{array}$ & 2013 & Article & $\begin{array}{l}\text { Comparing the } \\
\text { effectiveness of an } \\
\text { inverted classroom to a } \\
\text { traditional classroom in } \\
\text { an upper-division } \\
\text { engineering course }\end{array}$ & 81 & $\begin{array}{l}\text { IEEE Transactions on } \\
\text { Education }\end{array}$ & US \\
\hline $\begin{array}{l}\text { (5) Gannod, Burge } \\
\text { \& Helmick }\end{array}$ & 2008 & $\begin{array}{l}\text { Conference } \\
\text { paper }\end{array}$ & $\begin{array}{l}\text { Using the inverted } \\
\text { classroom to teach } \\
\text { software engineering }\end{array}$ & 71 & $\begin{array}{l}\text { International Conference } \\
\text { of Software Engineering }\end{array}$ & US \\
\hline (6) Prober \& Khan & 2013 & Article & $\begin{array}{l}\text { Medical education } \\
\text { reimagined: A call to } \\
\text { action }\end{array}$ & 50 & Academic Medicine & US \\
\hline
\end{tabular}


2012). Some studies specifically acknowledge active learning (Mason et al., 2013; McLaughlin et al., 2014), and one study also names blended learning (Strayer, 2012). These two concepts can also be found in a wide range of studies across the whole corpus.

In the six most-cited studies, the flipped approach is generally defined as a strategy that 'relies on technology to introduce students to course content outside of the classroom so that students can engage that content at a deeper level inside the classroom' (Strayer, 2012, p. 171). The core idea is to 'flip the common instructional approach', enabling the classroom to be a place 'to work through problems, advance concepts, and engage in collaborative learning' (Tucker, 2012, p. 82) by mixing 'the use of technology with hands-on activities' (Gannod et al., 2008, p. 777). These definitions rest on the assumption that flipped teaching alters traditional instruction so that deeper levels of learning can take place in class rather than rely on homework (Gannod et al., 2008; Mason et al., 2013; McLaughlin et al. , 2014; Prober \& Khan, 2013; Strayer, 2012; Tucker, 2012). The most common advantages expressed in the six most-cited publications are that the flipped classroom approach focusses student-centred and collaborative, problem-based learning activities, thus enabling teachers to spend more time identifying student problems and knowledge gaps (Mason et al., 2013; McLaughlin et al., 2014; Prober \& Khan, 2013; Strayer, 2012). They also indicate that the approach allows teachers to cover more course material (Mason et al., 2013) and engage directly with students when they are involved in in-depth learning activities (Gannod et al., 2008; Prober \& Khan, 2013; Strayer, 2012). Moreover, the publications suggest that the approach makes it possible to foster a 'shared responsibility between students and instructors' (McLaughlin et al., 2014, p. 242), and overall, optimising classroom time is often specifically emphasised (Gannod et al., 2008; Mason et al., 2013; McLaughlin et al., 2014; Tucker, 2012). The flip is usually referred to as a video clip (Gannod et al., 2008; Mason et al., 2013; Tucker, 2012), but other interactive technologies or materials such as textbooks and handouts are also mentioned (McLaughlin et al., 2014; Prober \& Khan, 2013; Strayer, 2012). The main advantage of using video clips to flip the classroom is described as enabling students to watch content as many times as needed (Prober \& Khan, 2013).

Most of the six most-cited publications focus specifically on the opportunities created by implementing the flipped classroom approach. However, there are some exceptions, with some results showing that students were less satisfied with how classroom structures oriented them to the learning content of the tasks in a course using the flipped classroom approach (McLaughlin et al., 2014). Even if they collaborated more, the students also reported having to adjust to different ways of orienting to the learning activities, including flips, minilectures, collaborative work and discussions with the teachers, whereas in the traditional classroom, the structure supporting the learning tasks was well established (Strayer, 2012). For the flipped classroom approach to be successful, it is argued that it is important to rigorously structure classroom activities and flips so that they coherently support one another. If the flip and the classroom activities are not carefully aligned, flips may instead become a barrier to the students' learning (Strayer, 2012). 
Across the six most-cited studies, the flipped classroom approach is also discussed in terms of a potential solution for teachers to respond to the increasing pressure to implement and use digital technologies in their teaching (Tucker, 2012). In one publication, the pros and cons of using video clips produced by private companies are discussed (Tucker, 2012), and the novelty of the flipped classroom approach is also questioned when it is argued that teachers have a tradition of asking students to prepare before class by, for example, doing readings (Strayer, 2012; Tucker, 2012). Instead, the novelty of the flipped classroom approach is described as 'the regular and systematic use of interactive technology in the learning process' (Strayer, 2012, p. 172). Furthermore, the stability of the approach is also considered in the publications as formal schooling and higher education has a long history of implementing instructional approaches that are later abandoned, indicating that 'there's a real danger that flipping, a seemingly simple idea that is profound in practice, may be reduced into the latest educational fad' (Tucker, 2012, p. 83).

As Table 2 shows, 4 of the 6 most-cited publications are journal articles. Among the 31 most-cited publications, 26 of the publications are journal articles, and only 4 are conference papers. This is in contrast somewhat to the slightly stronger conference paper discourse identified in step 1 of the review. Still, the second-mostcited publication in the field of flipped classrooms is a conference note on the development of the approach (Tucker, 2012). Although conference publications have high status in some disciplines, such as computer science, there is a clear preference for citing journal articles over conference papers in the field of flipped classrooms. An explanation for this can be that a journal article is often a more recent but also a more authoritative record of a study that has been validated by a more elaborate peer-review system. Of the 26 journal articles among the 31 most-cited publications (see Appendix 1), 4 were published in the American Journal of Pharmaceutical Education (10, 15, 16, 25), 3 in Academic Medicine (4, 7, 12), 2 in Phi Delta Kappan (23, 29), 2 in Computers \& Education (31, 36), 2 in Internet and Higher Education $(19,28)$. The remaining 13 articles were published in 13 different journals. This shows that a significant proportion of the most-cited journal articles were published in well-established, high-ranked journals. In particular, it suggests that medical and pharmaceutical education is influential as empirical contexts within the field of flipped classroom research, with educational technology journals beginning to gain some influence. This differentiation between subject-specific areas and more general and educational technology-based fields further adds credence to the perception that the field of flipped classroom research is rather siloed and fragmented and therefore still evolving.

While they are fragmented in terms of the subject area of interest, the mostcited publications are relatively homogenous when it comes to educational level of interest. Publications addressing higher education contexts make up 25 of the 31 most-cited publications, compared to only 4 publications addressing K-12 schools $(13,20,22,28)$. This is an interesting finding since the flipped classroom approach is regarded to have first emerged within $\mathrm{K}-12$ educational contexts (Ash, 2012). As will be discussed in the next section, many of these higher education publications rely on local case studies and aim to improve practice and student outcomes. 
Types of knowledge contributions based on flipped classrooms and their epistemological basis

This section details an epistemological-qualitative analysis to understand the knowledge foundations of flipped classrooms as a field of interest. In this analysis, we have coded the subset of the 31 most-cited publications (see Appendix 1) with regard to the types of knowledge contributions made. These relate to the following research characteristics: focus, methods, data, theory use, conclusions and the type of text contribution (note that the same publication can appear in more than one category). The results of this analysis are presented in Table 3.

As already established, 25 of the 31 records are from the higher education sector, leaving only 6 of the records from other educational areas $(2,7,13,20,22,28)$. The character of most of the publications is that they are locally situated in terms of their sample or case. In addition, 26 of the 31 publications (all but 2, 7, 13, 20, 22, 28) are based on teachers reporting their own practices and the context of a single higher education course or classroom experience or, similarly, a specific curricular aspect within a disciplinary subject area. The number of (mostly student) respondents in empirical studies varies but is most commonly between 20 and 40 for a smaller higher education course, with a few examples having over 500. Such small sample sizes for local case studies might not be a problem if the flipped classroom approach used in these studies was fully theorised and operationalised in terms of a specified design (e.g., of content, pedagogy, technology use, etc.). However, basic descriptions are often lacking, making high-quality empirical research characteristics rare amongst the 31 most-cited publications. Commonly, the flipped classroom approach is taken for granted as effective in improving student learning, and the experimental setting or flipped classroom approach used is not fully described. Added to this, the choice of methods is generally inappropriate for showing improved student learning or making in-depth qualitative analyses of whether learning occurred. A considerable number, 19 records, makes use of comparisons of student results or motivation changes within small sample settings. In 16 references, basic survey data, like course questionnaires or examples from students' pre- and post-tests, are often compared over two courses or between two courses

Table 3 Types of knowledge contributions based upon review sample $(N=31)$

\begin{tabular}{|c|c|c|c|}
\hline $\begin{array}{l}\text { Type of knowledge } \\
\text { contribution }\end{array}$ & Characteristics & Quantity & $\begin{array}{l}\text { Studies (identified by the } \\
\text { previous numbering, see } \\
\text { also Appendix 1) }\end{array}$ \\
\hline $\begin{array}{l}\text { Studies that are local in } \\
\text { character }\end{array}$ & $\begin{array}{l}\text { Studies of local course experiments, } \\
\text { subject-specific areas, case studies, etc. }\end{array}$ & 26 & $\begin{array}{l}1,3-10,12,14,15,17-20, \\
22-26,31-33,35\end{array}$ \\
\hline $\begin{array}{l}\text { Claims of improved student } \\
\text { learning and/or student } \\
\text { motivation }\end{array}$ & $\begin{array}{l}\text { Argue that Flipped classrooms enhance } \\
\text { student learning or motivation, often by } \\
\text { comparing with a traditional teaching } \\
\text { approach }\end{array}$ & 19 & $\begin{array}{l}3,4,6-10,12,14,15,17 \\
19,20,23-26,28-33,35\end{array}$ \\
\hline $\begin{array}{l}\text { Comparisons of Flipped } \\
\text { classrooms/Inverted } \\
\text { classrooms to other forms } \\
\text { provided }\end{array}$ & $\begin{array}{l}\text { Comparing Flipped classrooms/Inverted } \\
\text { classrooms (mainly) to traditional forms } \\
\text { of teaching }\end{array}$ & 16 & $\begin{array}{l}3-5,7-10,14,15,23,25 \\
26,30,32,33,35\end{array}$ \\
\hline $\begin{array}{l}\text { Opinion-based or reflection- } \\
\text { based arguments around } \\
\text { flipped classrooms }\end{array}$ & $\begin{array}{l}\text { Typically editorials, reflections or opinion } \\
\text { sections }\end{array}$ & 4 & $2,11,13,28$ \\
\hline $\begin{array}{l}\text { Learning/educational } \\
\text { theories are explicit }\end{array}$ & $\begin{array}{l}\text { Theoretical approach or understanding } \\
\text { is explicit and referenced }\end{array}$ & 11 & $\begin{array}{l}1,3,6,9,18,23,24,29 \\
31,33,35\end{array}$ \\
\hline
\end{tabular}


(based on simple dichotomies of traditional versus flipped approaches). This methodological trend is often accompanied with the dismissal of traditional teaching as unsuccessful with the flipped classroom positioned as a solution. Thus, an argument regularly used in the 31 most-cited publications is that the flipped classroom approach improves student learning, but this claim is mainly evidenced by improved student test results or student self-reports of increased motivation. This suggests that the mainly positive results reported in the research may be an effect of the bias of self-reported studies undertaken by teachers themselves but may also be related to the rhetorical conviction and current hype around the flipped classroom approach. Only 4 of 31 references $(2,11,13,28)$ are opinion or reflection papers, but opinion-based arguments around the flipped classroom approach are also common within the overall sample. These arguments tend to describe the flipped classroom approach uncritically, without scientific consideration of empirical design or reference to earlier research. It should be noted that rather than explicitly using and referring to educational or learning theories, most studies instead refer to a mix of pedagogical terms or strategies (e.g., active, blended, inquiry-based, problem-based, flipped, student-centred learning, etc.) without describing or theoretically distinguishing them fully. Equally, these pedagogical terms or strategies are generally not considered in relation to the context in which a study was conducted, developed or reported. Empirically and theoretically, many of the most-cited flipped classroom studies do not draw on systematic or existing resources from other research or on related fields such as educational technology. Only one study explicitly stated the theoretical aim of developing the field of flipped classrooms (29).

\section{Discussion and conclusions}

In this article, we investigated the current state of research on the flipped classroom approach based on the most-cited publications selected from a multidisciplinary database search and systematic review process. Our focus concerned research characteristics (focus, setting, methods and empirical data), knowledge contributions and how the research on flipped classroom as a field of interest interacts. Our aim was to describe and problematise the current research by relating it to the wider field of educational technology to discuss the kinds of future research needed. The research questions we asked were as follows:

- How can the field of interest around the flipped classroom approach be described and problematised based on the most-cited publications?

What characterises the studies in terms of focus, setting (educational system, academic subject and country), methods and empirical data? How does the research interact?

What kind of knowledge is this field of interest aiming at developing?

What can be said of the current state of the field as an approach and a movement and what future research is needed?

The current state of flipped classroom studies as a field of interest can be described, based on our analysis, as growing fast, with a slight conference 
preference and a focus on higher education and STEM area contributions, with the US as the predominant geographical context. It should be noted, however, that our systematic review was conducted based on database searches and citations of scientific publications in the English language, introducing a strong bias for certain geographical areas. Developments around flipped classrooms, especially outside the practices of higher education, are also taking form in other languages and in other, presumably faster, more ephemeral and more dispersed media than the ones examined. In particular, as social media and other usergenerated forms of knowledge-sharing arenas that cut across national- and cultural-specific boundaries characterise both the instructional approach and how it has spread internationally, such media and sharing practices should be of significant interest for further developing a deeper understanding of how the movement of flipped classroom is emerging socially and technologically. Ideologically, it connects to strong societal and educational discourses of opening and making learning resources more accessible, re-usable and sustainable.

Based on the source data and co-citations in our corpus of scientific publications, we conclude that studies on flipped classrooms are dominated by higher education sector studies and are relatively local in character. The research tends not to interact beyond the two clusters of general education/educational technology and subject-specific areas. This implies that knowledge contributions related to the flipped classroom approach are relatively siloed and fragmented and have yet to stabilise. Since our review was conducted, some systematic reviews have been published and compiled in special issues, indicating that the instructional approach and research designs around flipped classroom studies are gaining interest (see e.g. Song, Jong, Chang, \& Chen, 2017; Stöhr \& Adawi, 2018) which testifies to an expanding research field. However, as a future field of research, its potential lies in a stronger alignment and interaction between such disciplinary fields as educational science, educational technology and subject-specific didactics so that results and research designs can be compared and developed. Based on our qualitative, protocol-based screening, it was shown that academically and socially, the research, as a movement, is quite scattered, and only local evidence and experiences are available. Small-size, local case studies and simple designs combined with empirical data, such as course questionnaires and student preand post-test results, constitute a large part of the research. Systematic evidence on the effectiveness of the approach as well as qualitative analyses of actual student learning based on empirical data is still rare. This is similar to the conclusion in the review by O'Flaherty et al. (2015, pp. 93-94), which stated that robust evidence on the effectiveness of the flipped classroom approach based on longterm or empirical validation is lacking and that better indicators for student engagement and conceptual use are needed. Our review complements the review by O'Flaherty et al. (2015) by more comprehensively conducting a systematic review across the literature and thus generating a broader impression of the field of interest. In doing so, our conclusion is that there is commonly a mismatch between the models of instruction and research methodology used that is visible in the discrepancy between espoused and applied learning theories in research designs. 
Based on the full Scopus corpus of 530 records, we examined the cooccurrence of keywords amongst the author-selected keywords for each publication and found that active learning and blended learning stood out as specifically interesting with regard to our research questions concerning what kinds of knowledge the research on flipped classroom produces. The two themes are commonly regarded as operating on somewhat different levels. First, blended learning is a theme that considers education to be designed on a system level, whereas active learning considers education to be mediated by human practices. Examples from publications on flipped active learning show how constructivist and behaviourist learning theories are simultaneously used and how discoverybased learning instruction models are combined with a behaviouristicexperimental learning theory methodology. There is a notable absence of approaches to learning in theory, instructional models and methodology that explore more situated, observation-based aspects of the flipped classroom approach. The fact that active and blended learning as significant co-occurring keywords in the corpus implies that many studies are concerned with either system-organisational aspects or the social micropractice of the flipped classroom approach. This reflects the common understanding of the flipped classroom approach as reallocating education activities before class and creating meaningful interactive learning situations in class. However, as the theoretical and conceptual underpinnings are generally vague in the screened corpus, these aspects need further attention from future research.

To conclude, rigorous and empirically well-grounded studies currently seem to be rare in the research on flipped classrooms. Very few studies can make generalisable or transferrable knowledge claims and thereby contribute to the development of the field of interest around flipped classrooms. Therefore, it is difficult to identify when, under what circumstances and in what ways the flipped classroom approach might be relevant as a pedagogical choice. For future research, more systematic, both cumulative and empirically grounded knowledge is needed to build a stronger evidence base. Furthermore, a better anchoring in, for example, learning theory or instructional design or in established research methodologies from educational technology research traditions could improve the quality and usefulness of the flipped classroom approach. Our results and recommendations therefore support the conclusions of the earlier review by O'Flaherty et al. (2015) but also foreground the relative impact of the higher education sector, provide more systematic knowledge and offer a problematising stance on the siloed character of the research and its knowledge base. The problem of siloed research and an absence of a shared knowledge base and 'contribution awareness' beyond the clusters of educational technology and the STEM areas, for example, are well known within higher education research (Tight, 2014). In the case of higher education, siloed research is characterised by local cases within departments, subject areas, courses, etc. (Tight, 2012). Our results show that the research on flipped classrooms is similarly siloed, suggesting that achieving the goal of improving practice will be difficult if future research does not make explicit connections to earlier studies and results within the overall field of interest. 


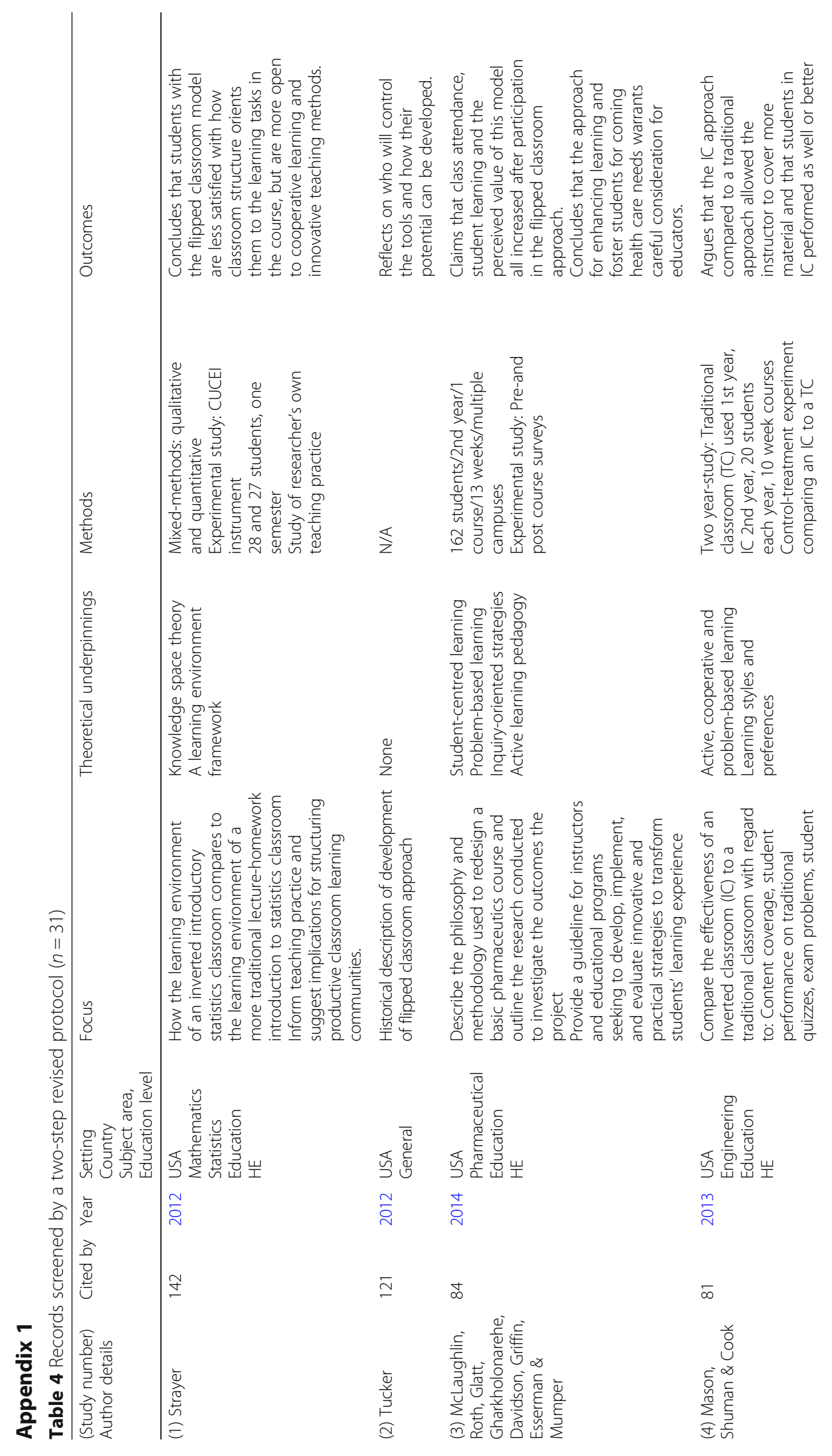




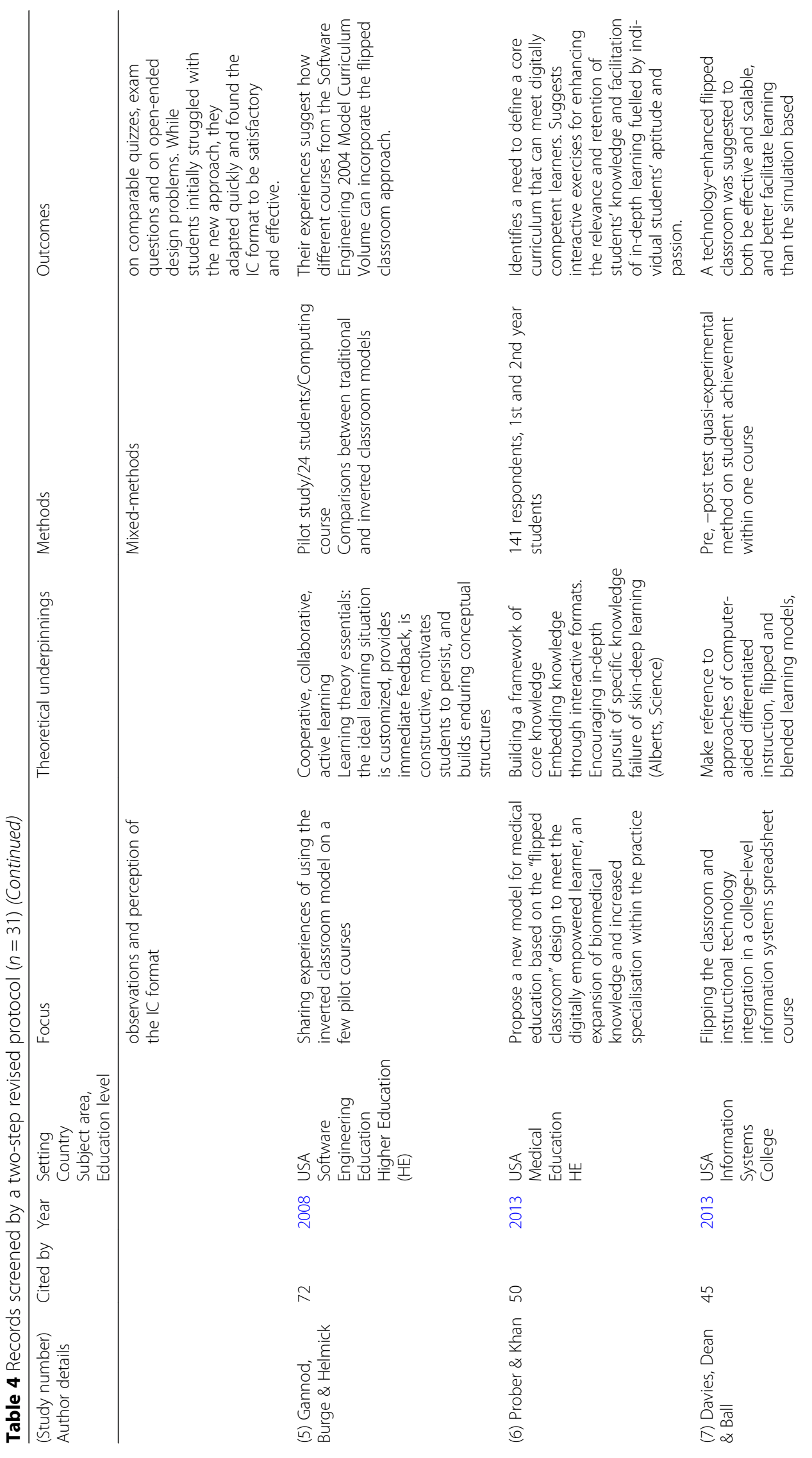




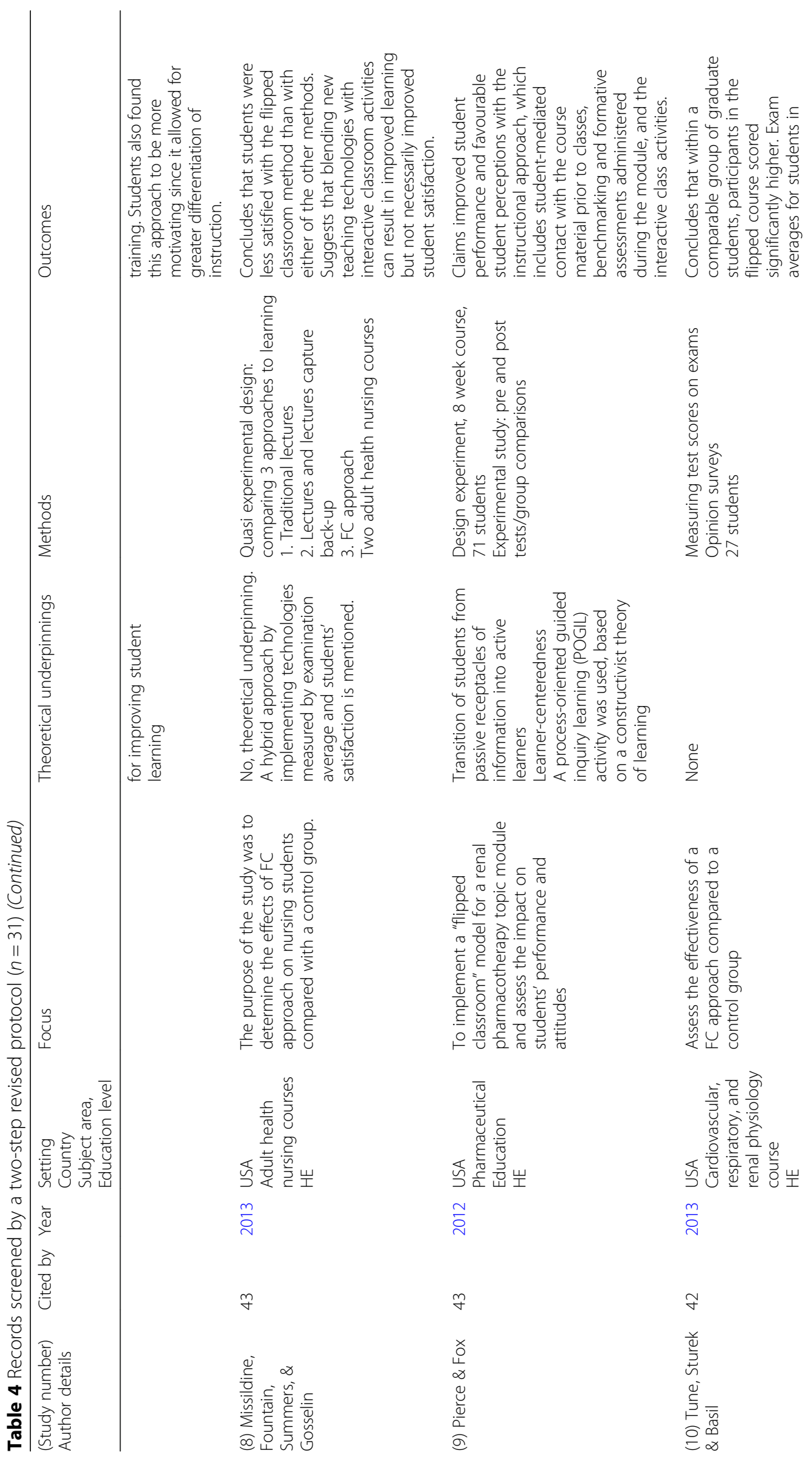




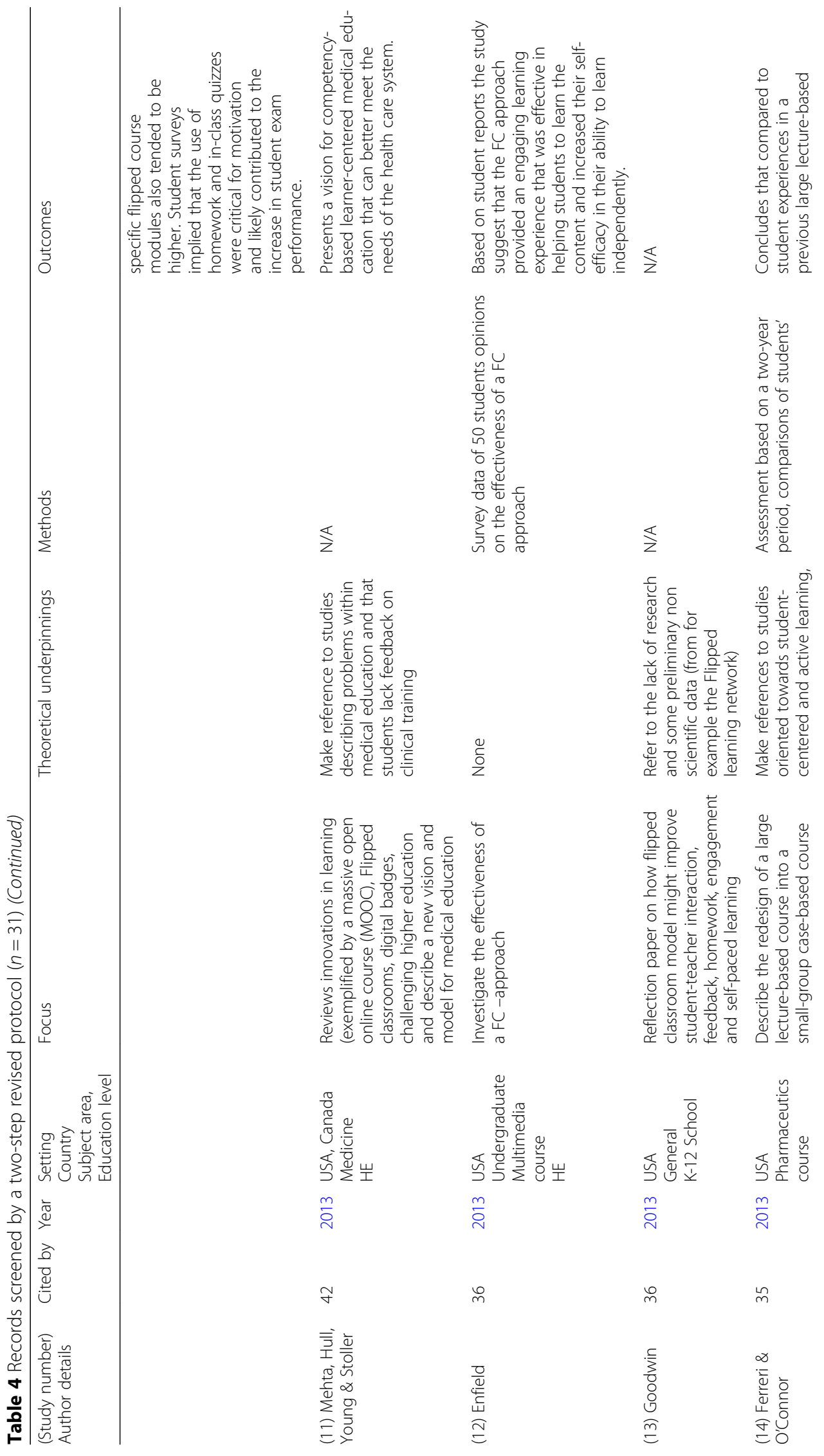




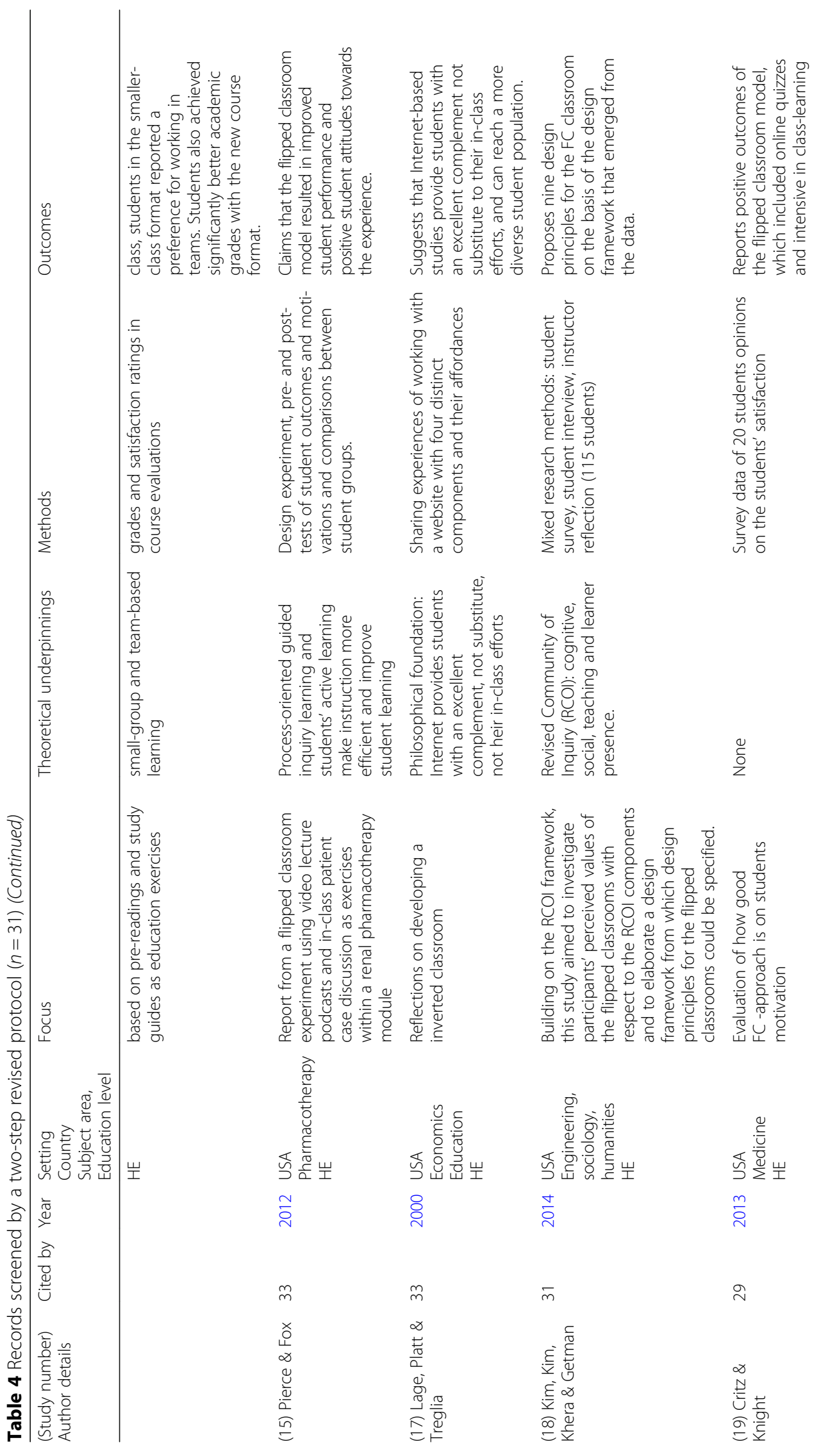




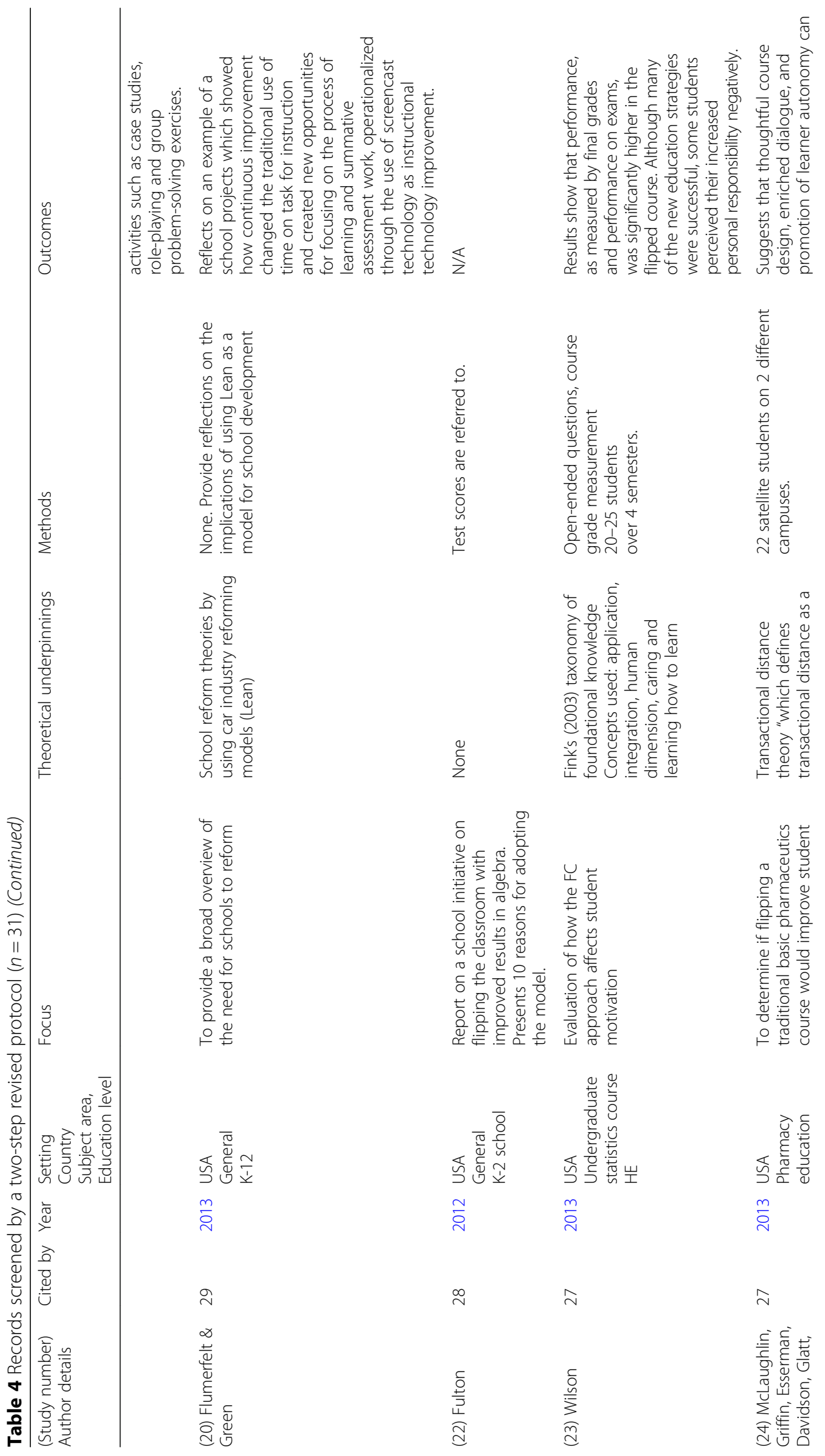




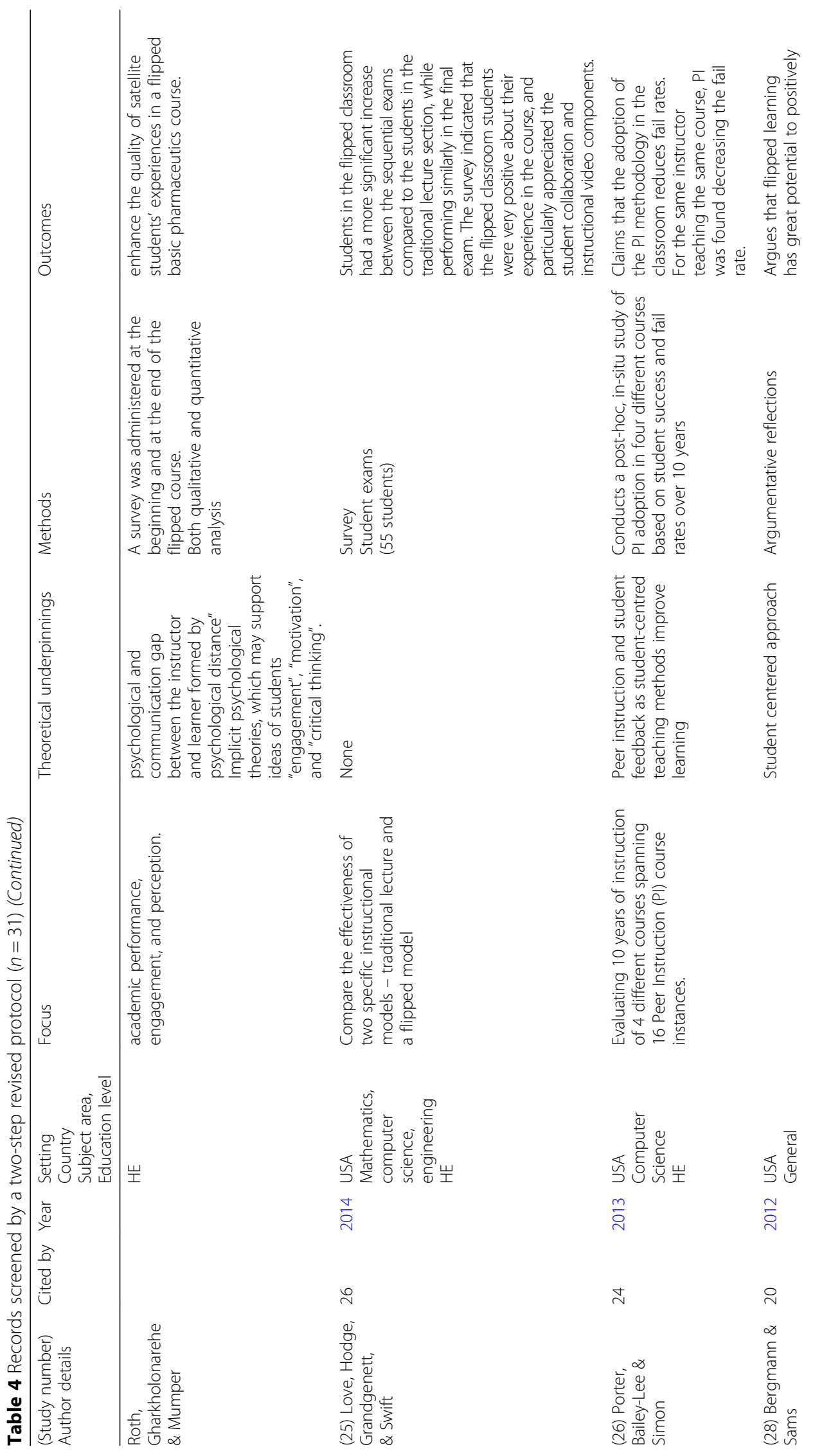




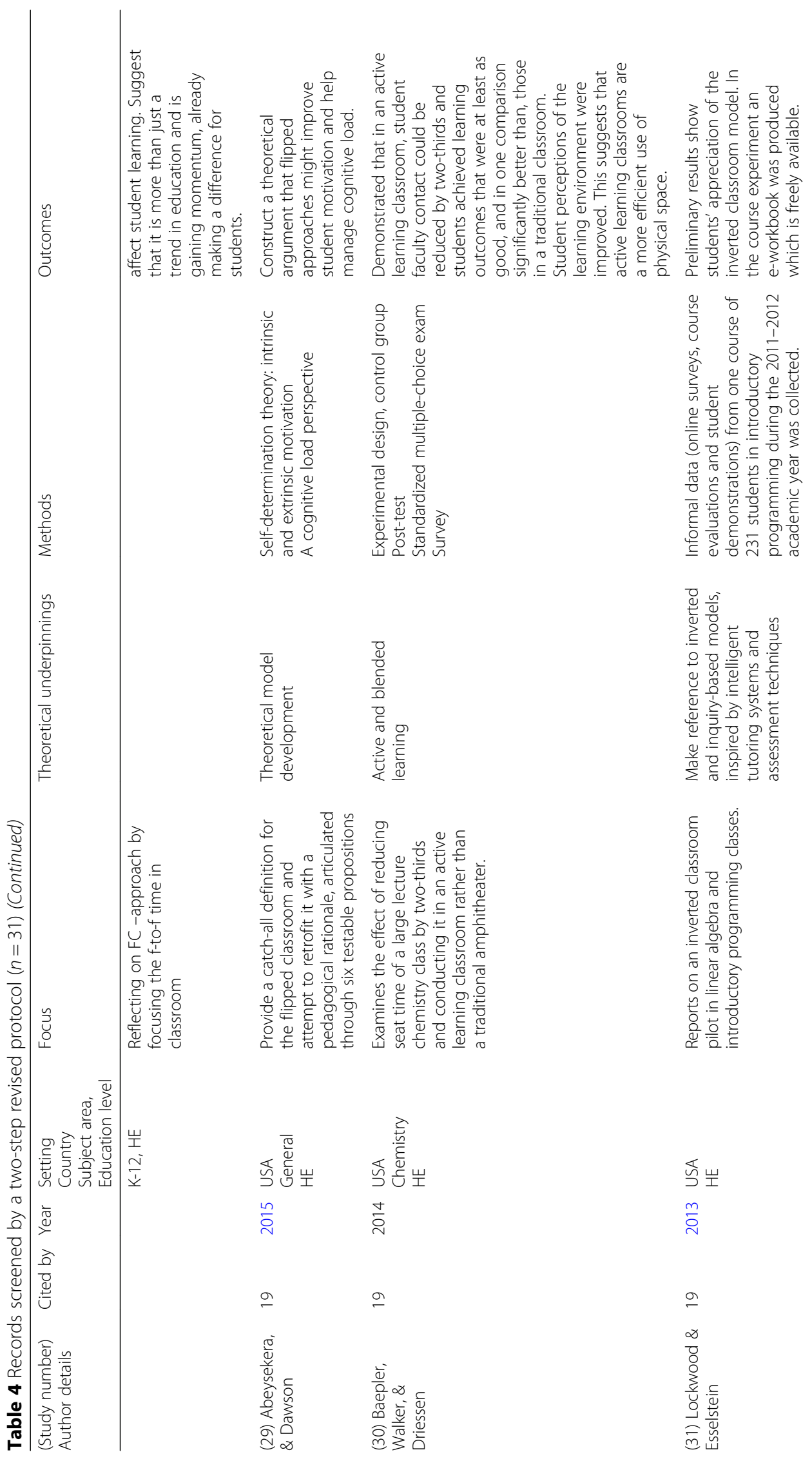




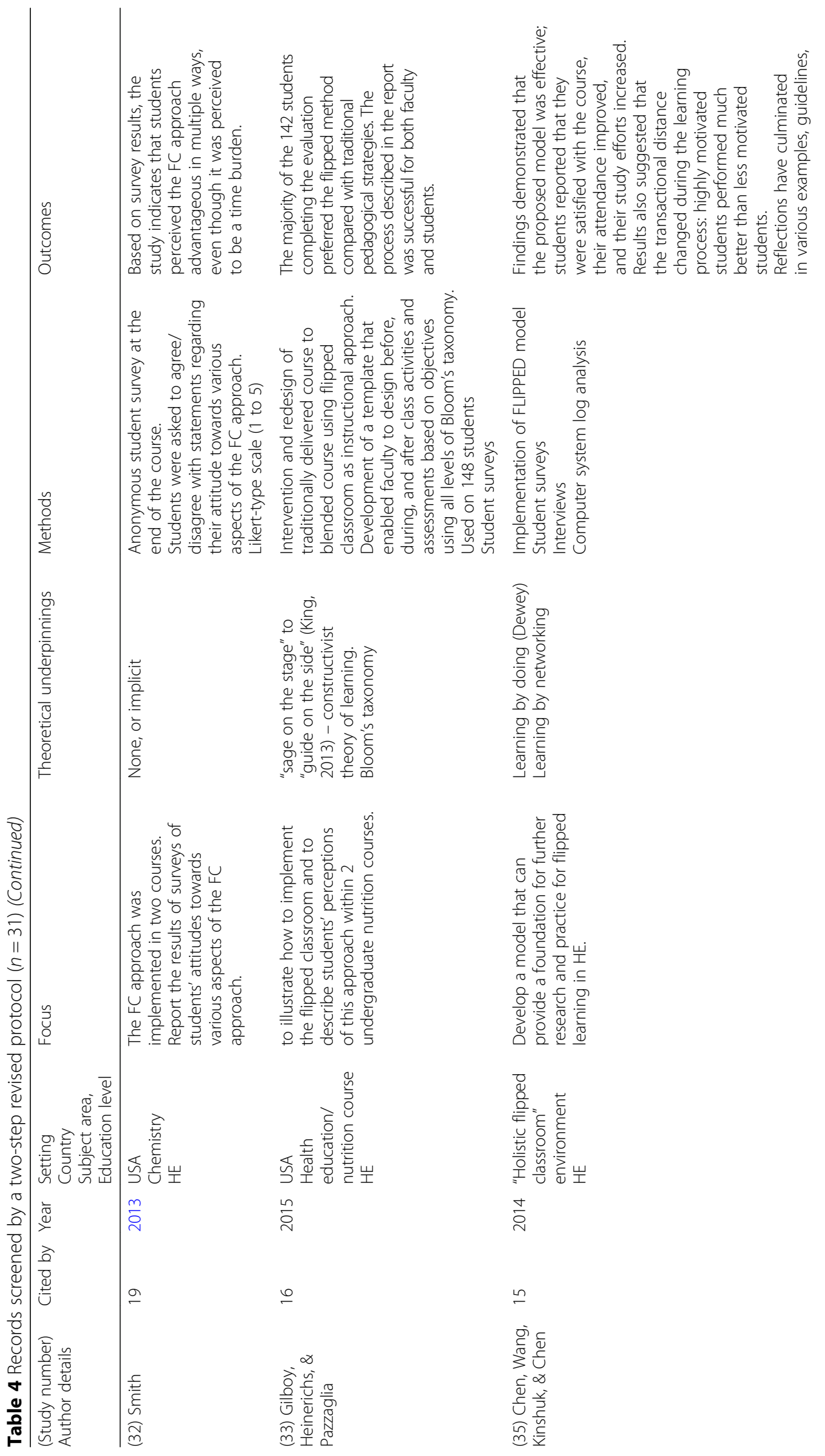




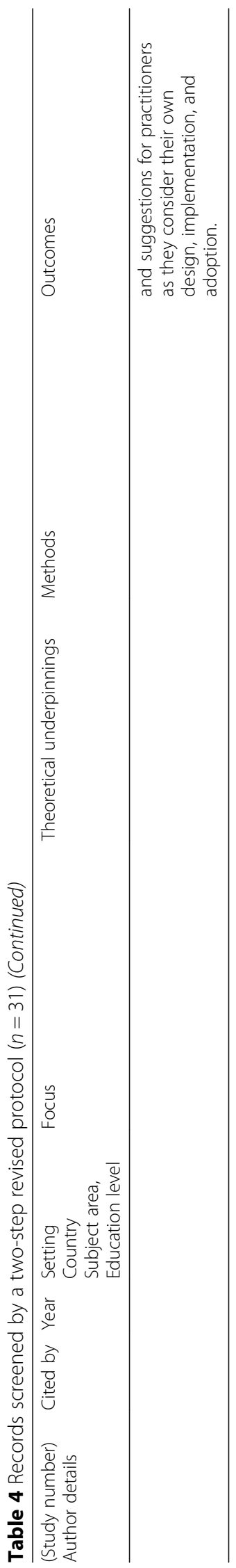




\section{Appendix 2}

Table 5 Records excluded after manual screening in step 2 of the review $(n=6)$

\begin{tabular}{|c|c|c|c|c|c|}
\hline $\begin{array}{l}\text { (Study number) } \\
\text { Author details }\end{array}$ & $\begin{array}{l}\text { Cited } \\
\text { by }\end{array}$ & Year & Author keywords & Title & Journal \\
\hline (16) Berridge et al. & 33 & 2012 & $\begin{array}{l}\text { ADHD; Prefrontal } \\
\text { Cortex; Cognition; } \\
\text { Methylphenidate; } \\
\text { Norepinephrine; } \\
\text { Dopamine }\end{array}$ & $\begin{array}{l}\text { Differential Sensitivity } \\
\text { to Psychostimulants } \\
\text { Across Prefrontal } \\
\text { Cognitive Tasks: Differential } \\
\text { Involvement of Noradrenergic } \\
a_{1} \text { - and } a_{2} \text {-Receptors }\end{array}$ & $\begin{array}{l}\text { Biological } \\
\text { Psychiatry }\end{array}$ \\
\hline (21) Rampton & 29 & 2002 & $\begin{array}{l}\text { Applied linguistics; } \\
\text { Code-switching; Foreign } \\
\text { languages; Interaction; } \\
\text { Language teaching; } \\
\text { Ritual }\end{array}$ & $\begin{array}{l}\text { Ritual and foreign language } \\
\text { practices at school }\end{array}$ & $\begin{array}{l}\text { Language in } \\
\text { Society }\end{array}$ \\
\hline $\begin{array}{l}\text { (27) O'Flaherty et } \\
\text { al }\end{array}$ & 22 & 2015 & $\begin{array}{l}\text { Higher education; } \\
\text { Flipped classroom; } \\
\text { Scoping review; } \\
\text { Educational outcomes; } \\
\text { Face to face teaching; } \\
\text { Engagement }\end{array}$ & $\begin{array}{l}\text { The use of flipped classrooms } \\
\text { in higher education: A scoping } \\
\text { review }\end{array}$ & $\begin{array}{l}\text { Internet and } \\
\text { Higher Education }\end{array}$ \\
\hline $\begin{array}{l}\text { (34) Valiente, } \\
\text { Swanson \& } \\
\text { Lemery-Chalfant }\end{array}$ & 16 & 2012 & $\begin{array}{l}\text { Temperament, } \\
\text { engagement; student- } \\
\text { teacher relationship }\end{array}$ & $\begin{array}{l}\text { Kindergartners' Temperament, } \\
\text { Classroom Engagement, and } \\
\text { Student-teacher Relationship: } \\
\text { Moderation by Effortful Control }\end{array}$ & $\begin{array}{l}\text { Social } \\
\text { Development }\end{array}$ \\
\hline $\begin{array}{l}\text { (36) Malmberg, } \\
\text { Hagger, Burn, } \\
\text { Mutton \& Colls }\end{array}$ & 15 & 2010 & $\begin{array}{l}\text { Classroom quality, } \\
\text { teacher-student } \\
\text { interaction, teacher } \\
\text { development, } \\
\text { multilevel model }\end{array}$ & $\begin{array}{l}\text { Observed Classroom Quality } \\
\text { During Teacher Education and } \\
\text { Two Years of Professional } \\
\text { Practice }\end{array}$ & $\begin{array}{l}\text { Journal of } \\
\text { Educational } \\
\text { Psychology }\end{array}$ \\
\hline $\begin{array}{l}\text { (37) Gelman \& } \\
\text { Nolan }\end{array}$ & 15 & 2002 & $\begin{array}{l}\text { Classroom activity; } \\
\text { Experimental design; } \\
\text { Fair coin. }\end{array}$ & $\begin{array}{l}\text { You Can Load a Die, But You } \\
\text { Can't Bias a Coin }\end{array}$ & $\begin{array}{l}\text { American } \\
\text { Statistician }\end{array}$ \\
\hline
\end{tabular}

\section{Acknowledgements}

This research is funded by the Swedish Research Council and conducted within the University of Gothenburg Leaning and Media Technology Studio (LETStudio) and the Linnaeus Centre for Research on Learning, Interaction and Mediated Communication in Contemporary Society (LinCs).

\section{Funding}

This research is funded by the Swedish Research Council.

\section{Availability of data and materials}

The dataset supporting the conclusions of this article comprise peer-reviewed scientific publications and these publications are included as references in the reference list.

\section{Authors' contributions}

All authors reviewed the research literature. The first author organized the review work and was main responsible for the development of the manuscript. All authors contributed to the analysis of the review. All authors read and approved the final manuscript.

\section{Competing interests}

The authors declare that they have no competing interests.

\section{Publisher's Note}

Springer Nature remains neutral with regard to jurisdictional claims in published maps and institutional affiliations. 
Received: 25 September 2017 Accepted: 28 March 2018

Published online: 24 May 2018

\section{References}

Abeysekera, L., \& Dawson, P. (2015). Motivation and cognitive load in the flipped classroom: Definition, rationale and a call for research. Higher Education Research and Development, 34(1), 1-14. https://doi.org/10.1080/ 07294360.2014 .934336$.

Ash, K. (2012). Educators view flipped model with a more critical eye. Education Week, 32(2), 6-8.

Bergmann, J., \& Sams, A. (2012a). Before you flip, consider this. Phi Delta Kappan, 94(2), 25.

Bergmann, J., \& Sams, A. (2012b). Flip your classroom: Reach every student in every class every day. Washington, DC: International Society for Technology in Education.

Berridge, C. W., Shumsky, J. S., Andrzejewski, M. E., McGaughy, J. A., Spencer, R. C., Devilbiss, D. M., \& Waterhouse, B. D. (2012). Differential sensitivity to psychostimulants across prefrontal cognitive tasks: Differential involvement of noradrenergic a 1- and a 2-receptors. Biological Psychiatry, 71(5), 467-473. https://doi.org/10.1016/j.biopsych.2011.07.022.

Biesta, G. (2007). Why "what works" won't work: The evidence-based practice and the democratic deficit in educational research. Educational theory, 57(1), 1-22.

Bishop, J. L., \& Verlinger, M. A. (2013). The flipped classroom: A survey of the research. Paper presented at the ASEE Annual Conference \& Exposition. Atlanta: American Society for Engineering Education.

Bulfin, S., Henderson, M., Johnson, N. E., \& Selwyn, N. (2014). Methodological capacity within the field of "educational technology" research: An initial investigation. British Journal of Educational Technology, 45(3), 403-414.

Cho, V., Ro, J., \& Littenberg-Tobias, J. (2013). What twitter will and will not do: theorizing about teachers' online professional communities. Learning Landscapes, 6(2), 45-62.

Critz, C. M., \& Knight, D. (2013). Using the flipped classroom in graduate nursing education. Nurse Educator, 38(5), 210213. https://doi.org/10.1097/NNE.0b013e3182a0e56a.

Davies, R. S., Dean, D. L., \& Ball, N. (2013). Flipping the classroom and instructional technology integration in a collegelevel information systems spreadsheet course. Educational Technology Research and Development, 61(4), 563-580. https://doi.org/10.1007/s11423-013-9305-6.

Denzin, N. K. (2009). The elephant in the living room: Or extending the conversation about the politics of evidence. Qualitative Research, 9(2), 139-160.

Duncan-Howell, J. (2010). Teachers making connections. Online communities as a source of professional learning. British Journal of Educational Technology, 41(2), 324-340.

Enfield, J. (2013). Looking at the impact of the flipped classroom model of instruction on undergraduate multimedia students at CSUN. TechTrends, 57(6), 14-27. https://doi.org/10.1007/s11528-013-0698-1.

Ferreri, S. P., \& O'Connor, S. K. (2013). Redesign of a large lecture course into a small-group learning course. American Journal of Pharmaceutical Education, 77(1), 13

Flores, Ò., del-Arco, I., \& Silva, P. (2016). The flipped classroom model at the university: Analysis based on professors' and students' assessment in the educational field. International Journal of Educational Technology in Higher Education, $13(1), 1-12$.

Flumerfelt, S., \& Green, G. (2013). Using lean in the flipped classroom for at risk students. Educational Technology and Society, 16(1), 356-366.

Fulton, K. P. (2012). 10 reasons to flip. Phi Delta Kappan, 94(2), 20-24.

Gannod, G. C., Burge, J. E., \& Helmick, M. T. (2008). Using the inverted classroom to teach software engineering, Paper presented at the International Conference on Software Engineering (pp. 777-786). https://doi.org/10.1145/1368088.1368198.

Gelman, A., \& Nolan, D. (2002). You can load a die, but you can't bias a coin. American Statistician, 56(4), 308-311. https://doi.org/10.1198/000313002605.

Goodwin, B. (2013). Evidence on flipped classrooms is still coming in. Educational Leadership, 70(6), 78-80.

Gough, D. (2007). Weight of evidence: A framework for the appraisal of the quality and relevance of evidence. Applied and Practice-based Research, 22(2), 213-228.

Hammersley, M. (2001). On 'systematic' reviews of research literatures: A narrative reply to Evans and Benefield. British Educational Research Journal, 27(5), 543-554.

Kalz, M., \& Specht, M. (2014). Assessing the crossdisciplinarity of technology-enhanced learning with science overlay maps and diversity measures. British Journal of Educational Technology, 45(3), 415-427.

Kim, M. K., Kim, S. M., Khera, O., \& Getman, J. (2014). The experience of three flipped classrooms in an urban university: An exploration of design principles. The Internet and Higher Education, 22, 37-50. https://doi.org/10.1016/j.iheduc 2014.04.003.

Lage, M. J., Platt, G. J., \& Treglia, M. (2000). Inverting the classroom: A gateway to creating an inclusive learning environment. The Journal of Economic Education, 31(1), 30-43.

Lage, M. J., \& Platt, G. (2000). The internet and the inverted classroom. Journal of Economic Education, 31(1), 11.

Lockwood, K., \& Esselstein, R. (2013). The inverted classroom and the CS curriculum, Paper presented at the SIGCSE 2013 Proceedings of the 44th ACM Technical Symposium on Computer Science Education (pp. 113-118). https://doi.org/10. 1145/2445196.2445236.

Love, B., Hodge, A., Grandgenett, N., \& Swift, A. W. (2014). Student learning and perceptions in a flipped linear algebra course. International Journal of Mathematical Education in Science and Technology, 45(3), 317-324. https://doi.org/10. 1080/0020739X.2013.822582.

Malmberg, L., Hagger, H., Burn, K., Mutton, T., \& Colls, H. (2010). Observed classroom quality during teacher education and two years of professional practice. Journal of Educational Psychology, 102(4), 916-932. https://doi.org/10.1037/a0020920.

Mason, G. S., Shuman, T. R., \& Cook, K. E. (2013). Comparing the effectiveness of an inverted classroom to a traditional classroom in an upper-division engineering course. IEEE Transactions on Education, 56(4), 430-435. https://doi.org/ 10.1109/TE.2013.2249066. 
McLaughlin, J. E., Griffin, L. M., Esserman, D. A., Davidson, C. A., Glatt, D. M., Roth, M. T., \& Mumper, R. J. (2013). Pharmacy student engagement, performance, and perception in a flipped satellite classroom. American Journal of Pharmaceutical Education, 77(9). https://doi.org/10.5688/ajpe779196.

McLaughlin, J. E., Roth, M. T., Glatt, D. M., Gharkholonarehe, N., Davidson, C. A., Griffin, L. M., ... Mumper, R. J. (2014). The flipped classroom: A course redesign to foster learning and engagement in a health professions school. Academic Medicine, 89(2), 236-243. https://doi.org/10.1097/ACM.0000000000000086.

Mehta, N. B., Hull, A. L., Young, J. B., \& Stoller, J. K. (2013). Just imagine: New paradigms for medical education. Academic Medicine, 88(10), 1418-1423. https://doi.org/10.1097/ACM.0b013e3182a36a07.

Missildine, K., Fountain, R., Summers, L., \& Gosselin, K. (2013). Flipping the classroom to improve student performance and satisfaction. Journal of Nursing Education, 52(10), 597-599. https://doi.org/10.3928/01484834-20130919-03.

Nouri, J. (2016). The flipped classroom: for active, effective and increased learning-especially for low achievers. International Journal of Educational Technology in Higher Education, 13(1), 33.

O'Flaherty, J., Phillips, C., Karanicolas, S., Snelling, C., \& Winning, T. (2015). The use of flipped classrooms in higher education: A scoping review. The Internet and Higher Education, 25, 85-95. https://doi.org/10.1016/j.iheduc.2015.02.002.

Park, Y., Yu, J. H., \& Jo, I. H. (2016). Clustering blended learning courses by online behavior data: A case study in a Korean higher education institute. The Internet and Higher Education, 29, 1-11.

Pierce, R., \& Fox, J. (2012). Vodcasts and active-learning exercises in a "flipped classroom" model of a renal pharmacotherapy module. American Journal of Pharmaceutical Education, 76(10), 196.

Porter, L., Bailey-Lee, C., \& Simon, B. (2013). Halving fail rates using peer instruction: A study of four computer science courses, Proceedings of the 44th ACM Technical Symposium on Computer Science Education (pp. 177-182). https://doi. org/10.1145/2445196.2445250

Prober, C. G., \& Khan, S. (2013). Medical education reimagined: A call to action. Academic Medicine, 88(10), 1407-1410. https://doi.org/10.1097/ACM.0b013e3182a368bd.

Rampton, B. (2002). Ritual and foreign language practices at school. Language in Society, 31(4), 491-525. https://doi.org/ $10.1017 /$ S0047404502314015

Selwyn, N. (2012). Ten suggestions for improving academic research in education and technology. Learning, Media and Technology, 37(3), 213-219.

Smith, J. D. (2013). Student attitudes toward flipping the general chemistry classroom. Chemistry Education Research and Practice, 14(4), 607-614. https://doi.org/10.1039/c3rp00083d.

Song, Y., Jong, M. S. Y., Chang, M., \& Chen, W. (2017). Guest editorial: "HOW" to design, implement and evaluate the flipped classroom? - A synthesis. Journal of Educational Technology \& Society, 20(1), 180-183..

Stöhr, C., \& Adawi, T. (2018). Flipped classroom research: from "black box" to "white box" evaluation. Education Sciences, 8(1), 22. https://doi.org/10.3390/educsci8010022.

Strayer, J. F. (2012). How learning in an inverted classroom influences cooperation, innovation and task orientation. Learning Environments Research, 15(2), 171-193. https://doi.org/10.1007/s10984-012-9108-4.

Tight, M. (2012). Researching higher education, (2nd ed., ). Maidenhead: Open University Press.

Tight, M. (2014). Working in separate silos? What citation patterns reveal about higher education research internationally. Higher Education, 68(3), 379-395.

Tucker, B. (2012). The flipped classroom: Online instruction at home frees class time for learning. Education Next, 12(1), 82-83.

Tune, J. D., Sturek, M., \& Basile, D. P. (2013). Flipped classroom model improves graduate student performance in cardiovascular, respiratory, and renal physiology. American Journal of Physiology - Advances in Physiology Education, 37(4), 316-320. https://doi.org/10.1152/advan.00091.2013.

Valiente, C., Swanson, J., \& Lemery-Chalfant, K. (2012). Kindergartners' temperament, classroom engagement, and student-teacher relationship: Moderation by effortful control. Social Development, 21(3), 558-576. https://doi.org/10. 1111/j.1467-9507.2011.00640.x

van Eck, N. J., \& Waltman, L. (2010). Software survey: VOSviewer, a computer program for bibliometric mapping. Scientometrics, 84(2), 523-538.

Westerman, D., Daniel, E. S., \& Bowman, N. D. (2016). Learned risks and experienced rewards: Exploring the potential sources of students' attitudes toward social media and face-to-face communication. The Internet and Higher Education, 31, 52-57.

Whitley, R. (2000). The intellectual and social organization of the sciences. Oxford: Oxford University Press.

Wilson, S. G. (2013). The flipped class: A method to address the challenges of an undergraduate statistics course Teaching of Psychology, 40(3), 193-199. https://doi.org/10.1177/0098628313487461. 